\title{
SLEEP HYGIENE AND HAPPINESS LEVELS OF UNIVERSITY STUDENTS STUDYING IN HEALTH-RELATED DEPARTMENTS
}

\author{
Hilal PEKMEZCI PURUT ${ }^{1 *}$, Burcu GENC KOSE ${ }^{1}$, Barıs TURKER ${ }^{1}$, Vacide ASIK OZDEMIR ${ }^{2}$, Bahar KEFELI \\ $\mathrm{COL}^{3}$
}

${ }^{1}$ Recep Tayyip Erdoğan University, Vocational School of Health Services, 53000, Rize, Turkey

${ }^{2}$ Recep Tayyip Erdoğan University, School of Health, 53000, Rize,Turkey

${ }^{3}$ Recep Tayyip Erdoğan University, Güneysu Vocational School of Physical Therapy and Rehabilitation, 53000, Rize, Turkey

\begin{abstract}
This study was planned in a descriptive and cross-sectional design to explore the sleep hygiene and happiness levels of university students studying in health-related departments and associated factors. The sample of the study comprised of 362 registered students at the Vocational School of Health Services between 1 and 30 January 2019, in the fall semester of 2019-2020. The "Descriptive Information Form" including socio-demographic characteristics and habits, the "Sleep Hygiene Index" and the "Oxford Happiness Questionnaire" were used to collect data. SPSS 21.0 program was used in the statistical analysis of the data. Arithmetic mean, standard deviation, minimum, maximum and percentage parameters were used in the distribution of the data. In this study, data were distributed normally, so parametric tests were used for statistical analysis. Student t-test was used for two independent variables and the One Way Anova test was used for more than two independent variables. Pearson correlation analysis was performed to examine the relationships between parameters. The study revealed that $80.9 \%$ of the students in the study were female, $62.2 \%$ lived in a state dormitory, $78.7 \%$ did not smoke, $60.5 \%$ slept an average of 6-8 hours a day, and $91.2 \%$ had no chronic disease. The mean Sleep Hygiene Index scores of smokers, men, those who studied in the anesthesia program, those stayed in the state dormitory, those who drunk caffeinated beverages after 18:00, those who slept for 8 hours or more, and those who woke up unrefreshed were found to be significantly higher $(\mathrm{P}<0.05)$. It was also observed that those who woke up refreshed had a significantly higher level of happiness $(\mathrm{P}<$ 0.05).
\end{abstract}

Keywords: Sleep, Sleep hygiene, Happiness, Student

*Corresponding author: Recep Tayyip Erdoğan University, Vocational School of Health Services, 53000, Rize, Turkey E mail: dteminetatar@gmail.com (E.TATAR ȘATIROĞLU U)

$\begin{array}{lll}\text { Hilal PEKMEZCI PURUT } & \text { (D) https://orcid.org/0000-0003-2157-4014 }\end{array}$

Burcu GENC KOSE (iD) https://orcid.org/0000-2332-5556-7677

Barıs TURKER, (D) https://orcid.org/0000-0001-7045-7573

Vacide ASIK OZDEMIR (iD) https://orcid.org/0000-0231-2123-0308

Bahar KEFELI COL (iD) https://orcid.org/0000-0002-2862-4451

Received: January 28, 2021

Accepted: February 12, 2021

Published: May 01, 2021

Cite as: Pekmezci Purut H, Genc Kose B, Turker B, Asik Ozdemir V, Kefeli Col B. 2021. Sleep hygiene and happiness levels of university students studying in health-related departments. BSJ Health Sci, 4(2): 129-135.

\section{Introduction}

Sleep, which is a basic human need that the body recharges itself for a healthy and long life, is related to the components of many biological and psychological structures that control cognitive functions and intracellular mechanisms, mainly the nervous system, and occurs as a result of a series of physiological events that develop simultaneously. Many regions of the brain such as cortical and subcortical play a role in the initiation and maintenance of sleep (Sahin and Aşçıŏlu, 2013). The World Health Organization reports that sleeping takes up one-third of life and is essential for physical, mental, and emotional health. A night of refreshing and quality sleep is required for a healthy and happy life. Sleep duration and quality are important indicators of quality of life (Shellene et al., 2016; Odabaşoğlu et al., 2017). The ideal sleep time for adults is recommended to be 7-9 hours a day (Soleimani et al., 2016; Ozdemir et al., 2015; WHO, 1998).
Sleep is regarded as a significant variable of health that affects an individual's quality of life and well-being (Kline, 2013). All the behaviors such as maintaining regular exercise and sleep/wakefulness program that facilitates falling asleep, preventing smoking, alcohol, and caffeine intake that have negative effects on sleep, avoiding daytime sleepiness and sleep routines are defined as sleep hygiene. The term 'sleep hygiene' was first used by Hauri to advice on improving patients' sleep problems (Hauri, 1977). Sleep hygiene is essential to improve sleep quality (Odabaşoğlu et al., 2017). Sleep hygiene rules and recommendations are presented in Table 1.

The disruption of sleep hygiene, and thus the quality of sleep, causes the individuals' emotions, thoughts, and motivation to deteriorate. The quality of life of the individual is also significantly affected. Quality of life can be expressed as happiness, satisfaction, and harmony. In other words, it includes the evaluation of what the 
individual perceives and the satisfaction and happiness she receives from them (Arslan and Fadıloğlu, 2009). Good sleep quality and fewer sleep problems have been associated with happiness and a positive impact on the adult population (Otsuka et al., 2020). Happiness has positive effects on protection from psychological disturbances, interpersonal communication, an increase of self-confidence, problem-solving, effective coping with stress, holistic thinking, and developing creativity skills (Büyükşahin et al., 2016; Unüvar et al., 2015; Temiz, 2015). The poor quality of sleep of university students studying in the health-related fields causes emotional and behavioral problems, negative mood, increased consumption of cigarettes, alcohol, and caffeine, as well as a decrease in academic success.

Table 1. Original sleep hygiene rules

\begin{tabular}{l} 
Sleep as much as needed to feel refreshed \\
and healthy during the following day, but not more. \\
Curtailing time in bed a bit seems to solidify sleep; \\
excessively long times in bed seem related to \\
fragmented and shallow sleep. \\
2 . A regular arousal time in the morning seems \\
to strengthen circadian cycling and to finally lead to \\
regular times of sleep onset. \\
3. A steady daily amount of exercise probably \\
deepens sleep over the long run, but occasional one- \\
shot exercise does not directly influence sleep during \\
the following night. \\
$4 . \quad$ Occasional loud noises (e.g. aircraft flyovers) \\
disturb sleep even in people who do not awaken \\
because of the noises and cannot remember them in \\
the morning. \\
$5 . \quad$ An excessively warm room disturbs sleep. \\
$6 . \quad$ Hunger may disturb sleep. A light bedtime \\
snack (especially warm milk or similar drink) seems \\
to help many individuals sleep. \\
$7 . \quad$ An occasional sleeping pill may be of some \\
benefit, but the chronic use of hypnotics is ineffective \\
at most and detrimental in some insomniacs. \\
8. Caffeine in the evening disturbs sleep. \\
$9 . \quad$ Alcohol helps tense people to fall asleep fast, \\
but the ensuing sleep is then fragmented. \\
$10 . \quad$ Rather than trying harder and harder to fall \\
asleep during a poor night, switching on the light and \\
doing something else may help the individual who \\
feels angry, frustrated, or tense about being unable to \\
sleep \\
\hline
\end{tabular}

Poor quality of sleep leads to a decrease in their academic performance, risk-taking, depression, and impaired social relationships (Kloss et al., 2010; Gaultney, 2016). The frequency of sleep problems among university students is reported to be between $19.2 \%$ and $57.5 \%$ (Feng et al., 2005). University students are particularly vulnerable to sleep disorders due to environmental factors such as reduced parental guidance and the freedom to choose their bedtime, increased academic stress, and increased time spent studying or extracurricular activities (Collete et al., 2014). It is observed that students sacrifice their sleep time and experience sleep problems, especially because educational programs in health fields are intensive and tiring, and environmental factors such as time spent for learning or extracurricular activities (Al-Kandari et al., 2017; Mayda et al., 2012). Research on university students has shown that poor quality of sleep is significantly associated with physical and psychological illness, as well as poor academic achievement and absenteeism. Members of the profession providing health services to the community must be in complete physical and mental well-being. The healthy lifestyle development and happiness of the students who will become members of this profession in the future and even care for sick/healthy individuals during their studentship period will also reflect on the society they serve and are role models (Collete et al., 2014; Angelika et al., 2012). In this study, it was aimed to determine sleep hygiene and happiness levels of university students studying in the field of health. This study will provide basic data for applications to increase sleep hygiene and happiness levels for students studying in the field of health and will contribute to the literature in this respect.

\section{Material and Methods}

\subsection{Study Universe and Sample}

This study was planned in a descriptive and crosssectional manner to determine the sleep hygiene and happiness levels of students studying in the field of health between January 1-30, 2019. The universe of the study was composed of students $(n=675)$ enrolled in physiotherapy, elderly care, anesthesia, first and emergency aid, medical laboratory techniques programs in Health Services Vocational School. No sample selection was made in the study. The data were collected by the researcher using face-to-face data collection method from the students (n: 372) who accepted the research and answered the whole questionnaire. Verbal information was given to the students before the research.

\subsection{Data Collection Tools}

\subsubsection{Descriptive information form}

The "Descriptive Information Form" developed by the researchers by reviewing the literature includes two sections to reveal the students' demographic characteristics (gender, age, department, grade, place of residence) and habits (smoking, drinking caffeinated beverages after 18:00, total sleep time, waking up refreshed, the presence of chronic disease and falling asleep in class) (Özdemir et al., 2015; Sahin and Aşçıoglu, 2012; Büyükşahin and Yıldız, 2016; Sahiner, 2017).

\subsubsection{The sleep hygiene index (SHI)}

The "Sleep Hygiene Index" was developed by Mastin et al. (2006). Its Turkish validity and reliability study was performed by Özdemir et al. (2015). The index includes 
13 questions and is rated on a five-point Likert scale (none: 1 , rarely: 2 , sometimes: 3 , often: 4 , always: 5 ). It aims to evaluate the presence of sleep hygiene by questioning how often the participant performs sleep behaviors that constitute sleep hygiene. The scores to be obtained on the scale ranges from 13 to 65 , and the higher score indicates poor sleep hygiene (Mastin et al., 2006; Ozdemir et al., 2015).

The items in the "Sleep Hygiene Index" are derived from the diagnostic criteria for inadequate sleep hygiene in the International Classification of Sleep Disorders. The Cronbach alpha value of the Sleep Hygiene Index in this study was calculated as 0.7 and was found valid and reliable.

\subsubsection{The oxford happiness questionnaire (OHQ)}

The Oxford Happiness Scale was developed by Hills and Argyle (2002) and adapted into Turkish by Doğan and Sapmaz (2012). Created to measure the happiness level of individuals, the questionnaire is a one-dimensional measurement tool with 29 items and 6-point Likert- type (1: Totally disagree, 6: Totally agree). The scale has no cut-off point, and as the score increases, the level of happiness increases. In Doğan's study, the internal consistency coefficient of the scale was found to be 0.91 . In this study, the Cronbach alpha coefficient of the Oxford Happiness Scale was 0.7 (Hills and Argyle, 2002; Doğan and Sapmaz, 2012).

\subsection{Inclusion Criteria}

The research was conducted with the students who attended the associate degree programs of Recep Tayyip Erdoğan University Health Services Vocational School and accepted to participate in the research.

\subsection{Data Collection and Analysis}

SPSS 21.0 program was used in the statistical analysis of the data. Arithmetic mean, standard deviation, minimum, maximum and percentage parameters were used in the distribution of the data. Histogram, skewness and kurtosis values and One Sample Kolmogorov Smirnov Test were used to determine whether the data were normally distributed. In the present study, data were distributed normally, so parametric tests were used for statistical analysis. Student t-test was used for two independent variables and the One Way Anova test was used for more than two independent variables. As a result of the tests, Tukey test, one of the post hoc test statistics, was used to determine the reason for the significant difference between more than 2 groups. Pearson correlation analysis was performed to examine the relationships between parameters. The results were evaluated at the confidence and significance level at a $\mathrm{P}<$ 0.05 .

\subsection{Ethical Considerations}

Written permission was obtained from Recep Tayyip Erdogan University for the research. (Protocol number: 16890724-900-E441 dated 30.11.2018). Since the use of the human phenomenon in the research requires the protection of individual rights, the condition of "Informed Consent" has been fulfilled as an ethical principle. In addition, the principle of "Respect for Human Dignity" was also taken into consideration in the study, and the "Privacy Principle" was adhered to by making a statement to the individuals participating in the study that the information about themselves would not be disclosed to others.

\section{Results}

The results showed that $80.9 \%$ of the students were female, $81.5 \%$ were between the ages of 16 and 20, $25.7 \%$ were trained in anesthesia, $25.7 \%$ were in first and emergency aid, $20.4 \%$ were in medical laboratory techniques, $19.9 \%$ were in physiotherapy, and $8.3 \%$ were in elderly care department. Besides, $54.7 \%$ of them were 2nd-grade students, $62.2 \%$ stayed in a state dormitory, $78.7 \%$ did not smoke, $40.9 \%$ sometimes drank caffeinated beverages after 18:00, 60.5\% slept 6-8 hours a day, $48.9 \%$ sometimes woke up refreshed, and $91.2 \%$ did not have a chronic disease (Table 2).

Table 2. Descriptive characteristics of students

\begin{tabular}{|c|c|c|c|}
\hline \multicolumn{2}{|c|}{ Descriptive Information } & \multirow{2}{*}{$\frac{N}{293}$} & \multirow{2}{*}{$\begin{array}{c}\% \\
80.9\end{array}$} \\
\hline & Female & & \\
\hline Gender & Male & 69 & 19.1 \\
\hline \multirow{2}{*}{ Age } & $16-20$ & 295 & 81.5 \\
\hline & $20+$ & 67 & 18.5 \\
\hline \multirow{8}{*}{ Department } & Anesthesia & 93 & 25.7 \\
\hline & First and & 93 & 25.7 \\
\hline & Emergency Aid & & \\
\hline & Medical & 74 & 20.4 \\
\hline & Laboratory & & \\
\hline & Techniques & & \\
\hline & Physiotherapy & 72 & 19.9 \\
\hline & Elderly Care & 30 & 8.3 \\
\hline \multirow{2}{*}{ Grade } & 1. grade & 164 & 45.3 \\
\hline & 2. grade & 198 & 54.7 \\
\hline \multirow{4}{*}{ Place of residence } & State dormitory & 225 & 62.2 \\
\hline & Private dormitory & 33 & 9.1 \\
\hline & Student house & 30 & 8.3 \\
\hline & Living with family & 74 & 20.4 \\
\hline \multirow{2}{*}{ Smoking } & Evet & 77 & 21.3 \\
\hline & No & 285 & 78.7 \\
\hline \multirow{3}{*}{$\begin{array}{l}\text { Caffeinated } \\
\text { beverage } \\
\text { consumption after } \\
\text { 18:00 }\end{array}$} & Yes & 140 & 38.7 \\
\hline & No & 74 & 20.4 \\
\hline & Sometimes & 148 & 40.9 \\
\hline \multirow{3}{*}{$\begin{array}{l}\text { Total hours of } \\
\text { sleep }\end{array}$} & 6 hours $\downarrow$ & 90 & 24.9 \\
\hline & 6-8 hours & 219 & 60.5 \\
\hline & $8+$ hours & 53 & 14.6 \\
\hline \multirow{3}{*}{ Wake up refreshed } & Yes & 39 & 10.8 \\
\hline & No & 146 & 40.3 \\
\hline & Sometimes & 177 & 48.9 \\
\hline \multirow[t]{2}{*}{ Chronic disease } & Yes & 32 & 8.8 \\
\hline & No & 330 & 91.2 \\
\hline Total & & 362 & 100.0 \\
\hline
\end{tabular}

The comparison of descriptive characteristics of the students and their SHI mean scores are presented in Table 3. SHI scores of smokers compared non-smokers, males compared to females, and those stayed in the state dormitory compared to those stayed with their student 
house and family were found to be significantly higher ( $\mathrm{P}$ $<0.05$ ). Besides, those who were educated in the anesthesia department had higher SHI scores than those in the physiotherapy $(\mathrm{P}<0.05)$. Those who drank caffeinated beverages after 18:00, those who slept for 8+ hours, and those who did not wake up refreshed also had significantly higher mean SHI scores than the other groups $(\mathrm{P}<0.05)$ (Table 3$)$.

Table 3. Comparison of SHI Scores According to the Descriptive information of the Students

\begin{tabular}{|c|c|c|c|c|c|}
\hline \multicolumn{2}{|l|}{ Descriptive Information } & $\mathrm{n}$ & X-SS & $\mathrm{t}$ & $\mathrm{p}$ \\
\hline \multirow{2}{*}{ Gender } & Female & 293 & $20.95-6.89$ & \multirow{2}{*}{-4.68} & \multirow{2}{*}{$0.02^{\mathrm{a}, \&}$} \\
\hline & Male & 69 & $23.84-7.29$ & & \\
\hline \multirow{2}{*}{ Age } & $16-20$ & 295 & $21.70-6.90$ & \multirow{2}{*}{1.16} & \multirow{2}{*}{$0.24^{\mathrm{a}}$} \\
\hline & $20+$ & 67 & $20.59-7.67$ & & \\
\hline \multirow{2}{*}{ Grade } & 1.grade & 164 & 21.92-7.16 & \multirow{2}{*}{1.04} & \multirow{2}{*}{$0.29 \mathrm{a}$} \\
\hline & 2.grade & 198 & $21.15-6.96$ & & \\
\hline \multirow{2}{*}{ Smoking } & Yes & 77 & $25.75-6.04$ & \multirow{2}{*}{6.26} & \multirow{2}{*}{$0.00^{a, \&}$} \\
\hline & No & 285 & $20.35-6.87$ & & \\
\hline \multirow{2}{*}{ Chronic Disease } & Yes & 32 & $23.03-7.79$ & \multirow{2}{*}{1.28} & \multirow{2}{*}{$0.20^{\mathrm{a}}$} \\
\hline & No & 330 & $21.35-6.97$ & & \\
\hline \multirow{5}{*}{ Department } & Anesthesia & 93 & $23.12-7.35$ & \multirow{5}{*}{3.15} & \multirow{5}{*}{$0.014 \mathrm{~b}, 8$} \\
\hline & Physiotherapy & 72 & $19.75-6.20$ & & \\
\hline & First and Emergency Aid & 93 & $22.23-6.91$ & & \\
\hline & Medical Laboratory Techniques & 74 & $20.82-7.14$ & & \\
\hline & Elderly Care & 30 & $20.06-7.25$ & & \\
\hline \multirow{4}{*}{ Place of residence } & State dormitory & 225 & $22.59-6.73$ & \multirow{4}{*}{9.83} & \multirow{4}{*}{$0.00^{\mathrm{b}, \&}$} \\
\hline & Private dormitory & 33 & $19.96-6.39$ & & \\
\hline & Student chouse & 30 & $23.56-7.05$ & & \\
\hline & Living with family & 74 & $18.02-7.11$ & & \\
\hline \multirow{3}{*}{$\begin{array}{l}\text { Caffeinated beverage } \\
\text { consumption after 18:00 }\end{array}$} & Yes & 140 & $24.00-7.06$ & \multirow{3}{*}{16.50} & \multirow{3}{*}{$0.00^{\mathrm{b}, ~ \& ~}$} \\
\hline & No & 74 & $19.02-7.57$ & & \\
\hline & Sometimes & 148 & $20.37-6.02$ & & \\
\hline \multirow{3}{*}{ Total hours of sleep } & 6 hours $\downarrow$ & 90 & $23.96-6.48$ & \multirow{4}{*}{14.35} & \multirow{3}{*}{$0.00^{\mathrm{b}, ~ \& ~}$} \\
\hline & 6-8 hours & 219 & $19.95-6.50$ & & \\
\hline & $8+$ & 53 & $23.71-8.42$ & & \\
\hline \multirow{3}{*}{ Wake up refreshed } & Yes & 39 & $16.79-7.47$ & & \multirow{3}{*}{$0.00^{\mathrm{b}, \&}$} \\
\hline & No & 146 & $24.13-7.00$ & \multirow[t]{2}{*}{23.72} & \\
\hline & Sometimes & 177 & $20.37-6.14$ & & \\
\hline
\end{tabular}

$\&=\mathrm{P}<0.05, \mathrm{a}=$ student $\mathrm{t}$-test, $\mathrm{b}=$ one-way ANOVA test.

In Table 4, the descriptive information of the students was compared with the Oxford Happiness Questionnaire mean scores, and it was seen that the mean Oxford Happiness Questionnaire scores of those who woke up refreshed were significantly higher than those who did not $(\mathrm{P}<0.05)$ (Table 4).

No significant relationship was found between the Oxford Happiness Questionnaire total score and Sleep Hygiene Index total scores in Table $5(\mathrm{P}<0.05)$.

\section{Discussion}

In this section, the results of this study conducted to investigate the sleep hygiene and happiness levels of university students studying at health-related departments and the associating factors are discussed with the relevant literature.

In our study, the SHI mean scores of male students were significantly higher than female students, which shows that male students have worse sleep hygiene. Odabaşoğlu et al. (2017) also determined the sleep hygiene of males worse than female ones (Odabaşoğlu et al., 2017). In another study conducted with students studying in the field of health, it was reported that sleep hygiene was worse in male students and therefore their sleep quality was lower. (Yazdi et al., 2016)

Nicotine in cigarettes causes sleep deprivation during the night, difficulty in falling asleep, and disruption of sleep by acting as a stimulant. Research shows that smokers have lower sleep quality than non-smokers. (Odabaşoğlu et al., 2017; Conway et al., 2008; Stipelman et al., 2013) Viai-Smitgh et al. (2009) found that the sleep quality of students who smoked was lower in a study with university students (Vail-Smith et al., 2009). Consistent with the literature, in our study the SHI mean scores of the students who smoked were found to be significantly higher. In other words, their sleep hygiene was lower.

In our study, the SHI mean scores of the students studying in the Anesthesia program were significantly higher than those who were educated in the Physiotherapy program, that is, their sleep hygiene was lower. This result may be due to the fact that the curriculum and practices of the students studying in the Anesthesia program are more intensive. In general, due to the intensive and tiring training programs carried out at universities that provide health education, students sacrifice their sleep times, and therefore their sleep quality decreases. (Mayda et al., 2012). Another study 
reports that while medical students have better sleep hygiene behaviors than other university students, their sleep quality is lower (Ahrberga et al., 2012; S Al-Kandari et al., 2017). In relevant studies, the sleep quality of students studying in the field of health was found to be poor (Zheng et al., 2008; Ghoreishi et al., 2008).
The SHI mean scores were examined according to students' place of residence, and it was seen that the SHI mean scores of those staying in the student house and state dormitory were significantly higher than those staying with their families.

Table 4. Comparison of students' descriptive information and the Oxford happiness questionnaire scores

\begin{tabular}{|c|c|c|c|c|c|}
\hline \multirow{2}{*}{ Descriptive Information } & & \multicolumn{4}{|c|}{ Oxford Happiness Questionnaire } \\
\hline & & $\mathrm{n}$ & X-SS & $\mathrm{t}$ & $\mathrm{p}$ \\
\hline \multirow{2}{*}{ Gender } & Female & 293 & $96.15-14.01$ & -0.69 & $0.49 \mathrm{a}$ \\
\hline & Male & 69 & $97.44-13.91$ & & \\
\hline \multirow{2}{*}{ Age } & $16-20$ & 295 & $95.88-14.15$ & & \\
\hline & $20+$ & 67 & $98.68-13.08$ & -1.48 & $0.13^{\mathrm{a}}$ \\
\hline \multirow{2}{*}{ Grade } & 1. grade & 164 & $95.10-14.12$ & -1.60 & $0.11^{\mathrm{a}}$ \\
\hline & 2.grade & 198 & $97.46-13.81$ & & \\
\hline \multirow{2}{*}{ Smoking } & Yes & 77 & $97.11-12.43$ & 0.506 & $0.506^{\mathrm{a}}$ \\
\hline & No & 285 & $96.20-14.39$ & & \\
\hline \multirow{3}{*}{ Chronic Disease } & Yes & 32 & $96.84-13.31$ & 0.18 & $0.85^{a}$ \\
\hline & No & 330 & $96.35-14.06$ & & \\
\hline & & $\mathrm{n}$ & X-SS & $\mathrm{F}$ & $\mathrm{p}$ \\
\hline \multirow{5}{*}{ Department } & Anesthesia & 93 & $94.76-14.47$ & 1.04 & $0.38^{\mathrm{b}}$ \\
\hline & Physiotherapy & 72 & $95.79-11.37$ & & \\
\hline & First and Emergency Aid & 93 & $96.52-13.88$ & & \\
\hline & $\begin{array}{l}\text { Medical Laboratory } \\
\text { Techniques }\end{array}$ & 74 & $97.25-15.10$ & & \\
\hline & Elderly Care & 30 & $100.43-15.48$ & & \\
\hline \multirow{4}{*}{ Place of residence } & State dormitory & 225 & $95.86-14.43$ & 0.32 & $0.81^{b}$ \\
\hline & Private dormitory & 33 & $97.33-16.43$ & & \\
\hline & Student House & 30 & $97.90-13.85$ & & \\
\hline & Living with family & 74 & $97.01-11.41$ & & \\
\hline \multirow{3}{*}{$\begin{array}{l}\text { Caffeinated beverage } \\
\text { consumption after 18:00 }\end{array}$} & Yes & 140 & $95.62-13.86$ & 1.40 & $0.24^{\mathrm{b}}$ \\
\hline & No & 74 & $98.81-13.80$ & & \\
\hline & Sometimes & 148 & $95.93-14.15$ & & \\
\hline \multirow{3}{*}{ Total hours of sleep } & 6 hours $\downarrow$ & 90 & 93.54-14.06 & 2.74 & $0.065^{b}$ \\
\hline & 6-8 hours & 219 & $97.62-13.34$ & & \\
\hline & $8+$ & 53 & $96.18-15.89$ & & \\
\hline \multirow{3}{*}{ Wake up refreshed } & Yes & 39 & $100.94-16.56$ & 4.94 & $0.008^{b, ~ \& ~}$ \\
\hline & No & 146 & $93.92-13.91$ & & \\
\hline & Sometimes & 177 & $97.44-13.10$ & & \\
\hline
\end{tabular}

$\&=\mathrm{P}<0.05, \mathrm{a}=$ student $\mathrm{t}$-test, $\mathrm{b}=$ one-way ANOVA test.

Table 5. Correlation between total scores of sleep hygiene and Oxford happiness levels

\begin{tabular}{llcc}
\hline & & \multicolumn{2}{c}{$\begin{array}{c}\text { Oxford Happiness } \\
\text { Questionnaire Total Score }\end{array}$} \\
\cline { 3 - 3 } $\begin{array}{l}\text { Sleep Hygiene } \\
\text { Total Score }\end{array}$ & Index & $\mathrm{P}=.26 \quad \mathrm{r}=-.05$ \\
\hline
\end{tabular}

This result suggests that students staying in student homes and state dormitories have low sleep hygiene because of staying with a large number of people, the decrease in parental guidance during sleep hours, the increase of academic stress, and the effect of environmental factors. In another study conducted with university students, the SHI mean scores of those staying in the state dormitory and private student house were found to be higher (Odabaşoğlu et al., 2017). Our results are consistent with the literature. It is known that consuming caffeinated beverages causes insomnia (Eisendrath et al., 2013). The SHI mean scores of the students who drank caffeinated beverages after 18:00 were found to be significantly higher than those who did not, or sometimes drank. Likewise, another study emphasized that $91.7 \%$ of students who consumed coffee had a higher frequency of poor quality of sleep than those who did not (Sarl et al., 2015). However, another study suggested that the consumption of caffeine-containing beverages such as tea and coffee did not affect the sleep quality of university students (Saygılı et al., 2011).

It is known that an ideal amount of sleep for an adult should be an average of 7-8 hours a day (Potter et al., 2009). In our study, those with 8 hour-sleep or more had significantly higher SHI scores than those who slept for 68 hours and 4-6 hours, so their sleep hygiene was worse. Consistent with our study, Aysan (2014) stated that the sleep quality of university students with less (4-5 hours) or more (more than 9 hours) sleep time was also worse (Aysan et al., 2015). These results indicate that sleep duration of more than 8-9 hours does not affect sleep quality positively; on the contrary, it may negatively affect sleep hygiene and thus sleep quality. 
Many of our students (n=146) woke up unrefreshed, and those waking up unrefreshed and sometimes waking up refreshed had significantly higher SHI scores, which means their sleep hygiene was much worse. When the total scores of sleep hygiene and happiness index were compared, although no significant relationship was found between them, the mean Oxford Happiness Questionnaire scores were found to be significantly higher for those who woke up refreshed than those who did not. This result highlights that those who wake up refreshed have higher sleep quality and are happier. Research cites that students with lower sleep quality may experience problems such as difficulty concentrating, comprehension, school attendance, fatigue, unhappiness, irritability, anxiety, and depression related to school life (Short et al., 2015). Otsuka (2020) argues that a person's happiness level is strongly associated with the prevalence of sleep problems (Otsuka et al., 2020). The decrease in the quality of sleep, which is defined as temporary unconsciousness, which constitutes an average of one-third of our lives, causes negative moods and individuals to be unhappy (Odabaşoğlu et al., 2017). In a study conducted with university students, sleep problems were observed more frequently in students who described their emotional state as unhappy (Sahiner, 2017). Aysan (2014) found that students who did not get up refreshed had worse sleep quality in a study with university students studying in the field of health (Aysan et al,. 2014). Karatay (2016) also reported that nursing students who described their academic success as poor had worse quality of sleep. (Karatay et. al., 2014) As a result, we can say that students with high sleep quality describe their academic success positively and those who get up refreshed describe themselves as happy.

\section{Conclusion}

In conclusion, our study, which was carried out to explore the sleep hygiene and happiness of students studying in health-related departments, revealed that sleep hygiene of male students was worse than female students, smoking, consumption of caffeinated beverages after 18:00, staying in a state dormitory, sleeping for 8 hours or more, waking up unrefreshed negatively affected sleep quality by reducing sleep hygiene, and waking up refreshed positively affected happiness.

With these results, it is recommended;

- to raise awareness of the relationship between smoking, alcohol/caffeinated beverage consumption, and sleep hygiene to promote the sleep quality and happiness levels of university students,

- to organize seminars and conferences to raise awareness on the benefits of happiness level on physical and psychological health and the effect of sleep hygiene on sleep quality, and

- to conduct further studies examining the relationship between sleep quality and happiness and academic achievement and to establish databases.

\section{Author Contributions}

HPP; initiated the research idea, developed, organized and wrote the manuscript. BGK; supervised the research, suggested the research methods, structured the paper and edited the manuscript. BT; analyzed and interpreted the data. VAO; analyzed and interpreted the data. BKC; manuscript editing.

\section{Conflict of Interest}

The authors declare that there is no conflict of interest.

\section{Limitations}

This research was conducted with the students of Recep Tayyip Erdogan University Health Services Vocational School associate degree program. The results of the study are only for this group. It cannot be generalized to all students studying in the field of health.

\section{References}

Ahrberga M. DresleraS. Niedermaierb A. SteigeraL.Genzela. 2012. The interaction between sleep quality and academic performance. J Psych Res, 46(12): 1618-1622.

Al-Kandari S, Alsalem A, Al-Mutairi S, Al-Lumai D, Dawoud A, Moussa M. 2017. Association between sleep hygiene awareness and practice with sleep quality among Kuwait University students. Sleep Health, 3(5): 342-345.

Al-Kandari S. 2017. Association between sleep hygiene awareness and practice with sleepquality among Kuwait University students. Sleep Health, (3):342-347

Angelika AS, Kulessa D, Gulewitsch MD. 2012. Sleep characteristics, sleep problems, and associations of selfefficacy among German university students. Nat Sci Sleep, 4: 1-7.

Arslan S, Fadıloğlu C. 2009. The effect on quality of life of sleep disorders in cancer patient. J Res Develop Nursing, 2: 16-27.

Aysan E, Karaköse S, Zaybak A, Ismailoğlu EG. 2014. Sleep Quality Among Undregraduate Students and Influencing Factors. Dokuz Eylul Univ Fac Nursing Electronic J, 7(3):193198.

Büyükşahin CG, Yıldız MA. 2016. The mediating role of selfesteem on the relationship between hopelessness and happiness in pedagogy formation students. Dicle Univ J Ziya Gökalp Fac Edu, 27: 96-107.

Conway SG, Roizenblatt SS, Palombini L, et al. 2008. Effect of smoking habits on sleep. Brazilian. J Med Biol Res, 41:722727.

Curcio G, Ferrara M, Gennaro L. 2006. Sleep loss, learning capacity and academic performance. Sleep Med Rev, 10: 323337.

Doğan T, Sapmaz F. 2012. Oxford mutluluk ölçeği Türkçe formunun psikometrik özelliklerinin üniversite öğrencilerinde incelenmesi. Düşünen Adam Psik Nörol Bilim Derg, (25): 297-304.

Eisendrath S, Lichtmachr J. Sleep Disorders. 2013. Current Medical Diagnosis and Treatment. In: Queen G, Papadakis M, McPhee S, editors. Lange \& Mc Graw Hill, USA, 51rd ed., pp. 1075-1078.

Feng S, Chen W, Yang Z, et al. 2005. Study on the status and quality of sleep-related influencing factors in medical college students. Zhonghua Liuxingbingxue Zazhi, 26: 328-331.

Gaultney JF. 2010. The prevalence of sleep disorders in college students: impact on academic performance. J Am Coll Health 
59(2): 91-97.

Ghoreishi A, Aghajani AH. 2008. Sleep quality in Zanjan University medical students. Tehran Univ Med J, 66(1):61-7.

Hauri P. 1977. Current Concepts: The Sleep Disorders. The UpjohnCompany, Kalamazoo, Michigan.

Hills P, Argyle M. 2002. The Oxford happiness questionnaire: a compact scale for the measurement of psychological wellbeing. Pers Individ Diff, 33:1073-108.

Kabrita SC, Hajjar-Muça TA, Duffy JF. 2014. Predictors of poor sleep quality among lebanese university students: association between evening typology, lifestyle behaviors, and sleep habits. Nature Sci Sleep, 6: 11-18.

Karatay G, Gürarslan Baş G, Aldemir H, Akay M, Bayır M, Onaylı E. 2016. Examining the Sleep Habits of Nursing Department Students and the Affective Factors. HSP, 3(1): 16-22.

Kline C. 2013. Sleep quality. In: Gellman MD, Turner JR, editors. Encyclopedia of behavioral medicine. Springer, New York, pp. 1809-1812.

Kloss JD, Nash CO, Horsey SE, Taylor DJ. 2010. The delivery of behavioral sleep medicine to college students. J Adolesc Health, 48(6): 553-561.

Mastin DF, Jeff B, Corwyn R. 2006. Assessment of sleep hygiene using the sleep hygiene index. J Behav Med, 29(3): 223-227.

Mayda AS, Kasap H, Yıldırım C. 2012. 4-5-6. Sınıf tıp fakültesi öğrencilerinde uyku bozukluğu sıklığı. Düzce Üniv Sağlık Bilim Enst Derg, (2):8-11.

Odabaşoğlu MO, Dedeoğlu T, Kasırga Z, Sünbül F. 2017. Sleep hygiene in university students. Gümüşhane Univ J Health Sci, 2017(4): 204-212.

Otsuka Y, Kaneita Y, Itani O, Maki Yoneatsu J, Susumu O, Hideyuki H, Aya K, Yuki K, Yoshimoto H. 2020. The relationship between subjective happiness and sleep problems in Japanese adolescents. Sleep Med, 69: 120-126.

Özdemir PG, Boysan M, Selvi Y, Yıldırım A, Yılmaz E. 2015. Psychometric properties of the Turkish version of the sleep hygiene index in clinical and non-clinical samples. Comprehen Psyc, 59: 135-140.

Potter PA, Perry AG. 2009. Fundamentals of nursing. Mosby Year Book, St Louis, Missour, 6rd ed., pp. 1198- 1227.

Sahin L, Așçıŏlu M. 2013. Sleep and regulation of sleep. J Health Sci, 22(1): 93-98.
Sahiner ÖG. 2017. Frequency of insomnia and depression symptoms in Selcuk University students and related factors. $\mathrm{PhD}$ Thesis, Selçuk University, Faculty of Medicine, Department of Public Health, Konya.

Sarı YO, Uner S, Büyükakkuş B, Bostancı OE, Celiköz AH, Budak M. 2015. Sleep quality and some factors affecting sleep quality in the students living in the residence hall of a university. TAF Preventive Med Bullet, 14(2): 93-100.

Saygılı S, Cil AA, Arıkan H, Dereli E. 2011. Sleepıng qualıty and fatıgue among university students Electronic J Vocational Colleges, 88-94.

Short MA, Louca M. 2015. Sleep deprivation leads to mood deficits in healthy adolescents. Sleep Med, 16(8): 987-93.

Soleimani F, Motaarefi H, Hasanpour-Dehkordi A. 2016. Effect of sleep hygiene education on sleep quality in hemodialysis patients. J Clinical Diag Res, 12(10): 1-4.

Stipelman BA, Augustson E, McNeelv T. 2013. The relationship among smoking, sleep, and chronic rheumatic conditions commonly associated with pain in the national health interview survey. J Behav Med, 36(5): 1-8.

Temiz YE. 2015. Erdeme dönüş psikoloji ve mutluluk yolu. Sakarya Üniv İlahiyat Fak Derg, 17: 273-277.

Ünüvar P, Çalışandemir F, Tagay Ö, Amini F. 2015. Preschool children's perception of happiness (Turkey and Afghanistan sample). Mehmet Akif Ersoy Univ J Edu Fac, 34: 1-22.

Vail-Smith K, Felts WM, Craig C. 2009. Relationship between sleep quality and health risk behaviors in undergraduate college students. College Student J, 43: 3 .

World Health Organization. 1998. Worldwide project on sleep and health: Project overview. https://apps.who.int/iris/bitstream/handle/10665/64100/ WHO_MSA_MND_98.3.pdf? sequence $=1$ \&isAllowed $=\mathrm{y}$ (accessed date: December 01, 2020).

Yazdi Z, Loukzadeh Z, Moghaddam P, Jalilolghad S. 2016. Sleep hygiene practices and their relation to sleep quality in medical students of Qazvin University of Medical Sciences. J Caring Sci, 5(2): 153-160.

Zheng J, Yang L, Chen Q. 2008. Effect of physical exercise on sleep quality in medical students. Chinese J Pub Health, 3:1218. 